\title{
Coping with Organizational Information Technology Events: A Perceived Organizational Support and Relationship-Focused Coping Perspective
}

\author{
Kuang-Yuan Huang \\ Colorado State University-Pueblo \\ kuangyuan.huang@ csupueblo.edu
}

\begin{abstract}
While in recent years there is an increasing interest in researching individual technology acceptance and use based on the stress-coping perspective, relatively little attention has been paid to social-contextual factors as the antecedents of individual coping strategies and coping outcomes. The research proposal is intended to address this limitation. Specifically, drawing on coping theory, organizational support theory, and research on organizational conflict management, a model on individual use of technology that incorporate perceived organizational support (POS) and positive/negative relationship-focused coping strategies is proposed. POS as a key coping resource during stress is expected to influence employees' primary and secondary appraisals of an IT event, which in turn affect their choices of positive/negative relationship-focused coping strategies, and the resulting technology use or nonuse. By considering the social aspect of coping, the proposed research is expected to bring additional insights to researchers and practitioners.
\end{abstract}

\section{Introduction}

During the past decade, there is an increasing number of information systems (IS) studies adopting coping theory to investigate information technology (IT) adoption and uses (e.g., [1-4]), owing to its abilities to explain both the cognitive- and emotional-aspects of individual behaviors $[3,5]$, the antecedents, processes and outcomes of IT uses [2], and both the adoption and disengagement of IT uses [5]. This stream of research conceptualizes user adaptation to organizational IT events - new IT implementations or significant modifications made to an existing IT in an organization [2] - as a process of stress and coping. Through the coping perspective, IT events trigger individual stress, which subsequently leads to behavioral and/or cognitive efforts aimed at either resolving problems associated with the IT event - problem-focused coping -, or managing the affected emotion - emotion-focused coping - to adapt to stress. These adaptation efforts then lead to various outcomes related to IT use or nonuse. IS researchers have adopted the coping framework to investigate IT events including the uses of healthcare IT [6], office productivity software [2, 5], mobile commerce [7], and security software [4], generating insights that complements other technology acceptance frameworks such as technology acceptance model (TAM) [8], Theory of Planned Behavior (TPB) [9], and unified theory of acceptance and use of technology (UTAUT) [10].

The coping framework introduces an alternative perspective allowing researchers to see organizational IT events as the process of stress and coping. However, extant IS studies adopting this framework have largely neglected the fact that IT acceptance and use involve not only the relationship between the user and technology, but rather they are also influenced by the socialcontextual factors surrounding the IT event [11]. Therefore, many technology acceptance models include social-contextual factors as key drivers of technology use. For example, UTAUT includes individual perceived social influence and facilitating conditions as the antecedents of technology use intention and behavior [10], and perceived visibility and image were introduced in Innovation Diffusion Theory (IDT) [12] as the antecedents of technology use. The consideration of social-contextual factors when studying technology use is especially critical in organizational settings where the introduction of information technology is a social phenomenon [13]. However, with only a few exceptions (e.g., [1, 5]), social-contextual factors have been missing in IS studies on technology acceptance and use that adopted the coping framework. This void results in three limitations for this stream of research.

First, it results in the oversight of the fact that during the stress-coping process, whether a stressor is appraised as threatening or not to an individual is dependent on the meaning of the event to the person [14, 15]. This subjective "meaning" of an event is a function of the relationship between the person's goals/beliefs and the environmental realities and conditions [14, 15]. It is a fundamental proposition of coping theory that, 
given the same event, depending on personenvironment relationship different meanings can be given to the event. As a result, the same event can be appraised differently by different people as harmful or beneficial. This evaluation and meaning-giving process is called "primary appraisal" by coping theorists [14, 16]. An understanding of the meanings people give to a technology is critical to understanding their interaction with the technology [11]. For coping researchers, there has been calls to identify the appraised meanings of situations, which underlie the way one copes, in order to explain individual choices of coping strategies [16].

Second, it leads to the negligence of social support - "the perception that one is cared for and esteemed by others, who could be called upon should the need arise" [17] (p. 395) - as a critical coping resource that one evaluates during the coping process $[16,18]$. In their seminal work, Lazarus and Folkman [16] defined coping as "the cognitive and behavioral efforts exerted to manage specific external and/or internal demands that are appraised as taxing or exceeding the resources of the person" (p. 141). This definition suggests that for an individual, whether a given situation is evaluated as stressful or not, and as challenging or threatening is in part "a function of his or her evaluation of coping resources" in context [16] (p. 167). Moreover, coping resources define a potential for coping efforts [19], that is, resource availability during stress determines what individuals draw on in order to cope [16]. Therefore, coping resources "precede and influence coping" [16] (p. 158). Lazarus and Folkman [16] called this evaluation of the availabilities of coping options and resources "secondary appraisal." Social support as a key coping resource has been found to positively affect individual coping evaluations and responses to stressful events [20], through both boosting one's self-esteem and self-efficacy, and successfully mobilizing support from others [17, 21]. In an organization, perceived support from an organization has been found to affect employees' confidence in their coping abilities [22]. In the IS discipline, while social support was studied in [1] as an antecedent of employees' coping responses to an organizational IT event, the theoretical mechanisms that lie behind the impacts of social support remain unclear.

The third limitation of not considering the socialcontextual factors of coping when studying IT acceptance and use is the negligence of the type of coping effort that focuses on the relational conflicts associated with stressful situations - relationshipfocused coping [21]. It has been pointed out the during organizational IT events, the stressor is not only the change itself, but also the relationship conflicts between end users and the organization, resulting in unanticipated outcomes [11]. In such a situation, successful coping depends "not only on our ability to keep our emotions under control and on our ability to resolve problems, but also on our ability to regulate our relationship with involved others" [21] (p. 229). Research on conflict management also suggests that strategies employees adopt to deal with relational conflicts are associated with individual job performance [23]. These arguments make relationship-focused coping - inter-personal regulation efforts such as negotiating, empathizing, or compromising aimed at maintaining (or disrupting) social relationships [21] critical for organizational IT events. The resolution of these relationship conflicts during an organizational IT event is expected to facilitate employee IT acceptance and uses [11]. IS studies on technology acceptance and use that adopt the coping framework have been emphasizing individually-centered (i.e., problemfocused and emotion-focused) coping strategies. The focus on user-organization conflicts during IT events has been missing in these studies.

By identifying these research limitations, I contend that it is imperative to consider the organizational social-contextual factors when applying the coping perspective to investigate organizational IT events. When facing an organizational IT event, the relationship between employees and the organization determines the evaluation of the meaning of the event (i.e., primary appraisal), which affects the strategies employees choose to cope with the event. Additionally, during the IT event employees' choices of copying strategies are also dependent upon the availability of coping resources (i.e., secondary appraisal), including the availability of social support. Moreover, employees' strategies to cope with the event also involve efforts to (positively or negatively) regulate employee-organization relationships. This social-driven coping process will eventually lead to employees' use (or nonuse) of the technology. In this paper a research model focusing on the relational antecedents of user coping during organizational IT events, and on the coping efforts targeting the regulation of social relationships relationship-focused coping -, is proposed. Specifically, drawing on coping theory, organizational support theory, and research on organizational conflict management, the proposed model conceptualizes employees' perceived organizational support (POS) as both an indicator of employee-organization relationship and a critical coping resource. As a key socialcontextual factor, POS is hypothesized in this study to influence employees' positive and negative relationship-focused coping efforts dealing with the relationship conflicts with the organization caused by organizational IT events. In turn, these relationshipfocused coping efforts are hypothesized to affect employees' IT uses. By considering the social aspect of coping during organizational IT events, the proposed 
context-focused and coping-based model is expected to extend extant IS research on IT acceptance and uses that adopt coping theory, and bring additional insights into individual coping process and IT uses.

The remainder of this paper is organized as follows. Background information about coping theory and perceived organizational support are reviewed in the next section. The subsequent section develops the proposed research model and hypotheses, which is followed by proposed research method and conclusion.

\section{Theoretical background}

\subsection{Coping theory}

An increasingly popular way of viewing individual responses to organizational IT events is through the coping perspective. Coping refers to individual behavioral and/or cognitive adjustments to stressful events - negative life events, chronic strains, and/or daily hassles [16, 19]. These stressful events create environmental, social, and/or internal demands that motivate individuals to address in order to prevent negative consequences and to restore internal or external equilibrium. People cope and adjust properly will have improved quality of life and/or mental and physical well-being, while ineffective coping is associated with negative behavioral, psychological, and physiological consequences [16, 24]. In an organizational setting, sources of stress include events in relation to job security, role ambiguity, work-life balance, resource and communication, and work overload [25, 26], activating employees' coping responses. Organizational change events, including IT change events, have been considered as a key stressor in organizational life [27]. Employees who cope with change events well have increased job satisfaction, organizational commitment, and job performance, while those who fail to adapt to change can have increased levels of absenteeism and turnover intention $[2,27,28]$.

To counter negative, and to promote positive, consequences of stressful events, people adopt different coping strategies. The coping strategies people undertake are commonly classified by coping researchers and practitioners as either problem-focused coping or emotion-focused coping [16]. People adopt problem-focused coping strategies with an attempt to approach, confront, and/or alter the situation itself. Examples of problem-focused coping strategies include actions directed at changing the environment (e.g., problem-solving efforts such as defining the problem, gathering information, identifying solutions, and acting upon the solutions), and actions geared toward the self (e.g., learning new skills, developing new standards of behavior) [16]. On the other hand, emotion-focused coping strategies are adopted to ameliorate and/or regulate the emotional reactions result from stressful circumstances [16, 29]. Emotional coping strategies can be inward-focusing (e.g., psychological distancing, positive situation reappraisal) and outward-focusing (e.g., escape-avoidance, seeking emotional support) [4, 16, 30].

According to [16, 31], one's choice of coping strategies is based on his/her cognitive evaluation of the stressful situation. This cognitive evaluation - the appraisal process - is to determine whether a particular situation is relevant to the well-being of the self and, if so, in what way [16]. This appraisal process can be further divided into two types - primary appraisal and secondary appraisal. Primary appraisal concerns the evaluation of whether one has anything at stake in a situation ("Am I in trouble or being benefited, now or in the future and in what way," [16] (p. 31). That is, the meaning of the situation to the person [14]. This individual-specific meaning, derived from the relationship between the person and the environmental reality, is created through the evaluations of individual motivational-relevance (the significance of the situation to the person) and motivational-congruence (the desirability of the situation to the person) $[14,16]$. Lazarus and Smith [14] gave an example to illustrate the idea that the same situation can be appraised differently based on the meanings given: for a distance runner, during training and practice, muscle pain and fatigue associated with a strenuous run are both highly relevant to the runner's goal (high levels of motivationalrelevance) and highly desirable (high levels of motivational-congruence). As a result, these events will be appraised positively by the runner. However, the same situation can be appraised quite negatively if the runner is struggling to finish a contest (due to high levels of motivational-incongruence). In the context of organizational IT events, an event's motivationalrelevance to employees as the end users of technology is expected to be high. On the other hand, whether an IT event is desirable or not will be determined by the level of congruence between employees' and the organization's beliefs and goals. This leads to variability in employees' coping strategies.

Primary appraisal of an event alone is not enough to determine one's coping response. An individual's coping response in the face of a stressful event is also dependent on the second type of appraisal, which involves the evaluation of the potential coping options, the feasibilities of these options, the availabilities of coping resources, and the capabilities of the self to carry out the identified options - secondary appraisal ("What if anything can be done about it?," [16] (p. 31). The evaluation of available options and resources is also context- and person-specific so as to address the specific 
person-environment relationship [16]. As a result, for the same event different people can evaluate and apply coping options differently. Together, the interplay of primary appraisal (perceived meaning) and secondary appraisal (perceived coping options and resource availability) affects the resulting perceived severity of a stressful event, and the strategies one choose to cope to overcome/prevent harm or to promote benefits [16, 19].

As indicated above, the evaluation of coping options and the ways people actually cope rely heavily on the availability of coping resources - social and personal characteristics upon which people may draw when dealing with stressors [16, 32]. Such resources available to assist one's coping efforts include personal health and energy, positive beliefs, self-esteem, problem-solving skills, and social support [16, 19]. Individual differences in secondary appraisal and coping response are partly due to differences in the availabilities of these coping resources. As a result, when facing difficulties, people high in self-esteem or perceived control - psychological coping resources are more likely to adopt problem-focused coping strategies [19]. Likewise, when experiencing stressful life events, people having access to social support social coping resource - appraise the stressors more positively and also cope more effectively than those who do not $[16,18,21]$. Coping resources therefore affect the outcomes of stress indirectly via affecting individual appraisal and coping processes. Additionally, possessing or having access to coping resources have also been found to have direct impacts on the outcomes of stress encounters (e.g., [18, 20,33]).

\subsection{Relationship-focused coping}

Social support as a critical coping resource suggests that healthy and quality social relationships can be instrumental during the times of stress and coping. That is, whether a relationship partner is evaluated as a potential coping resource for social support depends on the quality of relationship [21]. Quality social relationships are especially important during the coping process when the stressful situation involves relationship partners. Failure to consider the relational tension or conflict in this inter-personal context can negatively affect the outcome of coping efforts [21]. For example, caregivers dealing with stress resulting from caregiving activities can have an increased caregiving satisfaction and an improved wellbeing by maintaining positive relationships with patients [21, 34]. Relationship quality can also contribute to one's primary appraisal, which affects the perceived meaning of an event. For example, Colquitt et al. [35] found that the quality of supervisor-subordinate relationship (in the form of trust) is a key predictor of job-related uncertainty, which in turn determines whether an organizational change event is evaluated as harmful and threatening or not [36].

Given the importance of social relationships in influencing the coping process and coping outcomes, surprisingly little attention has been paid to social relationship as the target of coping efforts. As argued by Folkman and Moskowitz [37], "Although most models of coping view the individual as embedded in a social context, the literature on coping is dominated by individualistic approaches that generally give short shrift to social aspects" (p. 758). DeLongis and O'Brien [21] also suggested that while the primary focus of the extant coping research has been on coping strategies geared toward altering the stressful situation itself (problem-focused coping), or regulating emotions (emotion-focused coping), a successful coping may depend also on one's ability to maintain social relationships with others [21]. In other words, there are circumstances when coping efforts targeting social relationships, instead of the self or the stressor directly, can be adaptive. DeLongis and O'Brien [21] therefore proposed the term "relationship-focused coping" to link social factors and coping, which involves "cognitive and behavioral efforts to manage and sustain social relationships during stressful episodes" [39] (p. 18). Relationship-focused coping encompasses efforts to maintain (or disrupt) social relationships during the times of stress even when relationship itself is not the stressor. Relationship-focused coping strategies include efforts that can enhance relationships such as negotiating or compromising with involved others, considering the relationship partner's situations, and being empathic (positive relationship-focused coping strategies, [21]), and efforts aimed at disrupting relationships such as criticizing, ignoring, confronting, or minimizing contact with relationship partners (negative relationship-focused coping strategies, [21]). Relationship-focused coping strategies have been primarily studied in various healthcare contexts including caregiver stress (e.g., [34]), family and marital stress (e.g., [39]), and stress experienced by chronic disease patients (e.g., [40]) and by college students (e.g., [41]). In general, positive relationship-focused coping efforts are positively associated with adaptive outcomes such as caregiving satisfaction and marital satisfaction, and negative relationship-focused coping strategies predict individual depression, diminished self-efficacy, and/or other maladaptive outcomes.

Employees' relationship-focused coping strategies during stress are particularly relevant in the context of organizational change and organizational IT events. Researchers of organizational change have pointed out the importance of quality employee-organization relationships in fostering employees' acceptances of 
changes [42-44]. Strategies for resolving relational stresses and conflicts originated from changes in organizations have also been widely discussed in the organizational change literature (e.g., [45-47]). By applying the coping framework and relationshipfocused coping strategies to investigate organizational IT events, researchers will be able to unravel the causes of employees' different relationship-focused coping strategies and the outcome IT use or nonuse.

\subsection{Perceived organizational support as coping resource}

The idea behind perceived organizational support (POS), according to organizational support theory [48, 49], is that based on employees' receptions of favorable or unfavorable treatments from an organization, employees develop a general perception concerning the extent to which the organization values their contributions and well-beings. POS is also about employees' belief that aid will be available from the organization when needed. Drawing on social exchange theory, and specifically norm of reciprocity, organizational support theory suggests that employees high in POS, that is, employees believes that they are valued and are treated well by the organization, will be obliged to return favor to the organization [50]. Employees' increased efforts contributing back to the organization also come with an increased expectation that their performance will be further rewarded, and an increased trust that they will be supported with needed resources by the organization in the case of stressful events $[49,51]$. This social exchange process leads to beneficial outcomes of both.

When dealing with stressful events, employees evaluate available coping resources, including the perceived availability of support from the organization. The anticipation that support will be available bolsters employees' self-esteem and coping self-efficacy during stress [49]. It also increases the likelihood that employees will actively seek support from organizations as coping assistance [52]. In this regard, POS as a resource increases one's coping potential and therefore affects one's secondary appraisal of stressful events in an organization. Additionally, from the perspective of conservation-of-resource theory [53], people are motivated to accumulate, protect, and retain valuable internal and external resources for the attainment of personal objectives, and environmental circumstances as stressors often gradually deplete these resources, leading to stressful outcomes. POS as a resource is able to prevent resource losses and promote perceived stability of life $[49,54]$. POS is therefore an important factor to consider when applying the coping framework to the organizational context.

\section{Research hypotheses}

Figure 1 illustrates the proposed research model, which is based on coping theory, organizational support theory, and research on organizational conflict management. In the proposed model, POS is conceptualized as a key contextual factor representing the relationship between an employee and the environment. This person-environment relationship affects the employee's primary appraisal - motivational relevance and motivational congruence of an IT event to the employee. Additionally, POS as a coping resource also affects employees' secondary appraisal. Together, POS contributes to employees' adoptions of positive and negative relationship-focused coping strategies, which lead to IT use or nonuse.

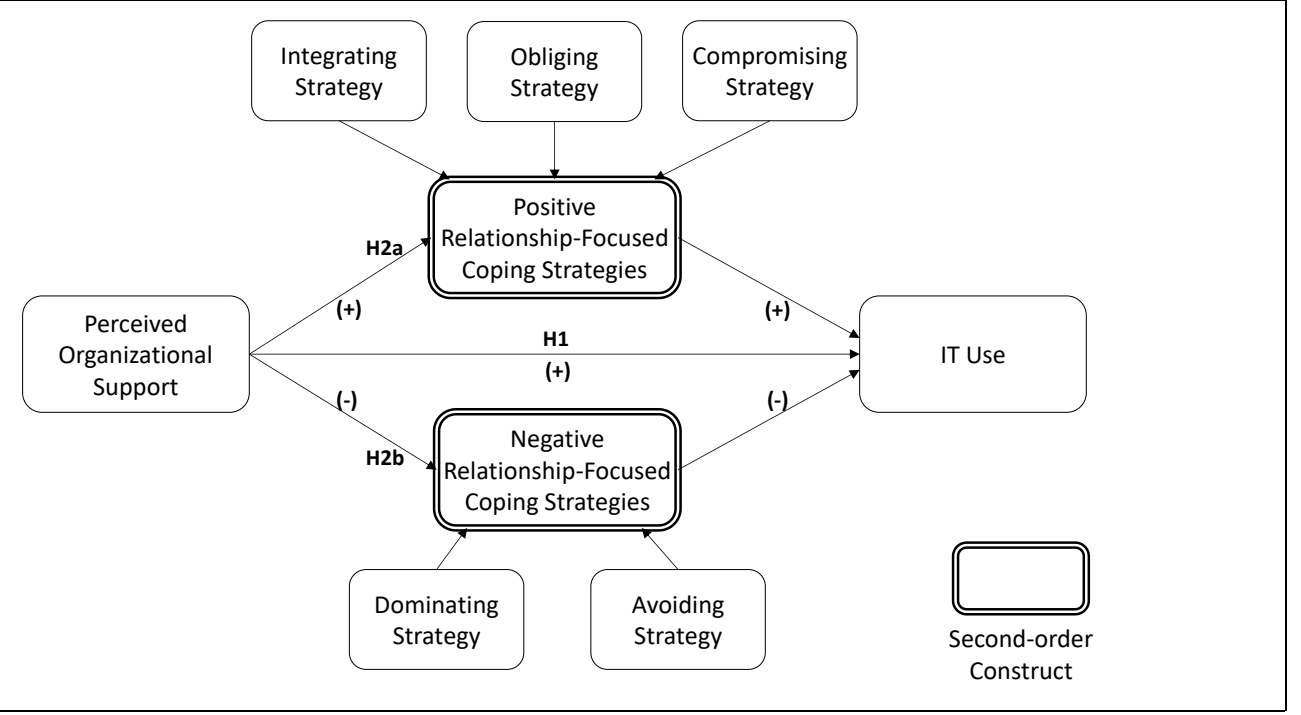

Figure 1. Research model 


\subsection{Direct effect of POS on IT use}

I hypothesize that during organizational IT events, employees with high levels of POS will be more likely to use the new technology. According to organizational support theory, POS create a felt obligation motivating employees to contribute back to the organization and to care about the organization's welfare [48, 49]. This leads to an increased commitment to the organization. Additionally, POS fulfills employees' needs for approval, affiliation, and support, contributing to their identification with the organization [49]. The increased commitment to, and identification with, the organization will foster employees' cooperative behavior and increase their willingness to pursue the goal of the organization [49]. Therefore, when an organization adopts a new technology, employees with high levels of POS will be motivated to use it.

Further, according to coping theory, during primary appraisal individuals ascribe meanings to an event. This appraisal process involves two components motivational relevance and motivational congruence [14]. While an organizational IT event would be motivational relevant and significant to employees, whether employees evaluate the event as motivational congruence or not will be determined by their levels of POS. For those with high POS, their motivations to contribute back to the organization will be congruent with the organization's goal of new IT adoption and implementation. That is, their intention to support and care about the organization's welfare makes the IT event a desirable one and not a threat to them. Further, POS serves as a coping resource during secondary appraisal increases employees' perceived competence to cope with the IT event [22], which enhances their interest and involvement in the event [51]. Together, primary and secondary appraisals of the IT event will therefore lead to the use of the new technology. Based on the above discussion, I hypothesize that:

H1. Perceived organizational support is positively and directly associated with IT use.

\subsection{Indirect effect of POS on IT use}

I also hypothesize that the choice of positive or negative relationship-focused coping strategies, which is affected by POS, will determine employees' decision to use or nonuse the technology.

While research on positive and negative relationship-focused coping strategies in an organizational setting is limited, research on organizational conflict management sheds lights on this coping process. Changes in organization are often associated with conflicts in relationships, motivating resolution efforts $[55,56]$. It has also been suggested that the success of organizational IT events depends on the resolution of associated relational conflicts $[11,55]$. Different typologies of strategies adopted by employees for resolving relational conflicts have been proposed in the organizational conflict management literature. For example, [57] differentiated three categories of conflict resolution strategies: collaboration, confrontation, and avoidance/yielding. [58, 59] classified one's conflict styles along two dimensions - high vs. low concern for self, and high vs. low concern for others -, resulting in five conflict resolution strategies: integrating, obliging, dominating, avoiding, and compromising:

- Integrating strategy (high concern for self and others) involves openness, collaboration, and examination of differences to reach an effective solution acceptable to both parties.

- Obliging strategy (low concern for self and high concern for others) is associated with cooperative behavior in order to preserve relationships and satisfy the needs and concerns of the other party.

- Dominating strategy (high concern for self and low concern for others) is associated with forcing and competing behavior, ignoring the needs and expectations of others in order to win or prevail.

- $\quad$ Avoiding strategy (low concern for self and others) is adopted by individuals who physically and/or psychologically withdraw and refuse to participate in conflict.

- Compromising strategy (intermediate concern for self and others) involves give and take behavior in order to make a mutually acceptable decision.

The general idea of these different typologies is that whether a conflict and its outcomes are positive or negative are dependent on the resolution strategies one chooses [23, 57]. For example, employees adopting more integrating and less avoiding strategies to resolve conflicts tend to have higher job performance [23]. Through examining the relationship between conflict resolution strategies and the outcomes of an information systems development project, [55] found that integrating strategy was positively associated with, whereas avoiding and dominating strategies were negatively related to, satisfactory conflict resolution. In this regard, this classification of conflict resolution strategies parallels relationship-focused coping strategies to deal with stressors. Specifically, employees' engagements in cooperative strategies that show concern for others - integrating, obliging, or compromising strategies - either enhance or preserve relationships [55, 59, 60, 61]. Therefore, these conflict resolution strategies can be considered as positive relationship-focused coping strategies. On the other hand, competitive approaches for resolving conflicts avoiding and dominating strategies - are harmful to 
relationships $[55,62]$, and therefore can be regarded as negative relationship-focused coping strategies.

For employees who perceive that they are supported by the organization, they tend to adopt positive relationship-focused coping strategies during conflict and stress. POS fosters employees' cooperative behavior and increases their concern for the organization due to the positive effects of POS on individual commitment and identification [48, 49]. These employees will also increase their engagements in organizational IT initiatives with the expectation of future rewards. Therefore, those with high levels of POS, when experiencing conflicts with the organization, tend to adopt positive relationship-focused coping strategies. Furthermore, as has been pointed out above, during primary appraisal of an IT event, the high motivational congruence between employees with high levels of POS and the organization will lead to a positive evaluation of the event. Additionally, during secondary appraisal, these employees' perceived high event controllability due to their perceived support availability from the organization will increase their task interest and involvement in the event [51]. The combination of these primary and secondary appraisals will contribute to employees' evaluation of the event as an opportunity rather than a threat. This is expected to increase their tendency to engage in cooperative resolution behavior, rather than competitive behavior, when conflicts occur, to preserve the relationship with the organization and to pursue mutual benefits. By adopting positive relationship-coping strategies, employees' perceived success of the organizational IT initiative, and the perceived quality of technology will be fostered [55]. Their perceived relationship with the organization and their engagement in the IT event will also be promoted [23]. These contribute to their increased IT uses.

On the contrary, employees high in POS will be less likely to engage in negative relationship-focused coping strategies to compete and harm their relationship with the organization. This is because POS is negatively associated with withdrawal behavior and absenteeism, and positively contributes to one's job satisfaction and affective attachment to the organization [49]. Further, since the adoption of negative relationship-focused coping strategies is associated with reduced relationship and job satisfaction and reduced job engagement [6365], employees adopt negative relationship-focused coping strategies, especially those adopt the avoiding strategy, are expected to reduce their use of the new technology. Together, I hypothesize that POS is positively associated with IT use also thorough reduced negatively relationship-focused coping strategies.

H2. Perceived organizational support is positively and indirectly associated with IT use through: a) increased positive relationship-focused coping strategies, and b) reduced negative relationship-focused coping strategies.

\section{Proposed method}

Survey data will be collected from a large U.S.based university to test the proposed model. The target university is planning to implement a new learning management systems (LMS) to improve the efficiency of student and course management. Using LMS to upload teaching materials and manage student records is encouraged but not mandatory in the target university. The voluntary nature of the IT event makes it appropriate for this study. Web-based survey will be distributed to faculty members scheduled to teach both in fall 2020 and spring 2021. To ensure that postimplementation stress and conflict due to the new LMS do not affect faculty members' POS, survey data will be collected during two different time periods. In fall 2020, before the new LMS is implemented, faculty members will receive a questionnaire containing items measuring their POS. Subsequently, in spring 2021, during/after the LMS implementation, those who responded the first survey will be contacted again and survey data about their positive and negative relationship-focused coping strategies for dealing with the IT event, and their resulting IT use or nonuse, will be collected. The expected sample size is 150 respondents.

Measurement scales from the extant literature will be adapted to measure the constructs in the proposed model. Specifically, POS will be modeled as a reflective construct measured using items adapted from the short form of the Survey of Perceived Organizational Support (SPOS) [48]. Positive and negative relationship-focused coping strategies are modeled as second-order formative constructs formed by the five conflict management styles - integrating, obliging, dominating, avoiding, and compromising [58] - as first-order reflective constructs (see figure 1). The two second-order constructs are modeled as formative ones because conceptually these two constructs do not exist independent of their corresponding five first-order constructs. Additionally, these five first-order constructs are not conceptually inter-changeable. Modeling the positive and negative relationship-focused coping strategies as formative constructs is therefore appropriate [66]. The Rahim Organizational Conflict Inventory-II (ROCI-II [58]) will be used to measure the five conflict management style constructs. Lastly, respondents' levels of organizational IT use will be modeled as a reflective construct measured using items adapted from [3].

Partial Least Squares (PLS) will be used to test the proposed model and hypotheses. As a Structural Equation Modeling (SEM) technique, PLS will allow the author to test and estimate the significance of the 
hypothesized relationships among multiple independent and dependent constructs simultaneously [67]. Different from Covariance-Based SEM (CB-SEM) that emphasizes model fit, PLS-SEM focuses more on model predictions and thus is suitable for exploratory research [68], like this proposed study.

Guidelines provided in [69] will be used for validating the measurement model. Specifically, for reflective constructs, factor loadings and cross-loadings will be used to examine indicator reliability. Additionally, convergent validity of the constructs will be assessed through average variance extracted (AVE), and composite reliability (CR) will be used to test internal consistency reliability of the reflective indicators. Lastly, discriminant validity will be tested by calculating the square roots of the AVE for each reflective construct and comparing them to the corresponding inter-construct correlations. Regarding the formative constructs, construct validity will be evaluated via examining the path weights of their forming indicators, and model reliability will be checked through multicollinearity test. SmartPLS 3.0 software package [70] will be used for data analysis.

\section{Expected contributions, limitations, and conclusion}

Drawing on coping theory, organizational support theory, and research on organizational conflict management, this study is intended to investigate the relationships among POS, positive and negative relationship-focused coping strategies, and the use of technology. By considering the social-contextual factors of coping, this study addresses the limitations of extant IS studies adopting the coping framework to investigate IT acceptance and use. The outcomes of this study will provide additional insights into employees' responses to organizational IT events. This study will not only extend the existing IS literature on this research stream and provide future research opportunities, it will also help managers design organizational change management strategies that take into account POS as a key socialcontextual factor. The findings of this study are also expected to guide employees to harvest valuable organizational relational resources, which will foster organization-employee relationships and eventually assist them to cope with organizational IT events.

This study has some limitations that require further investigation. First, this study proposes to collect data about the use of one type of technology in the university setting. Whether the result of the study will hold when considering other technology and organization types is unknown. Future research that builds on this study to evaluate different IT events and different organizational contexts will provide more generalizable results. Next, the proposed study is based on the cross-sectional examination of individual perceptions. Thus, the detailed processes of employees' primary and secondary appraisals, and their applications of different coping strategies, are missing. Additionally, this study, being positivist in nature, is unable to discover and interpret the detailed meanings lying behind employees' coping decisions and behaviors. Future research will complement and expand the findings of this study by employing a variety of research methods such as interview and longitudinal observations. Third, this study models positive and negative relationship-focused coping strategies as second-order constructs, along with their hypothesized relationships with POS and IT use. This model, while being parsimonious, could not reveal the detailed effects of the five conflict management styles as first-order constructs on IT use. Future studies that examine these individual effects will be able to generate additional insights for research and practice.

Lastly, this study considers relationship-focused coping strategies as employees' only coping responses to organizational IT events. Additionally, in this study POS is the only social-contextual factor affecting employees' coping responses. A more comprehensive result characterizing various coping options available to employees and their consequences will be generated by incorporating problem-focused and emotion-focused coping strategies, and by incorporating other socialcontextual factors such as employee-supervisor relationships, into the model.

To conclude, this study will advance our understanding of the social aspect of IT acceptance from the coping perspective. It is hoped that the result of this study will stimulate additional insightful research.

\section{References}

[1] H. Bala and V. Venkatesh, "Adaptation to Information Technology: A Holistic Nomological Network from Implementation to Job Outcomes," Management Science, vol. 62, no. 1, 2015, pp. 156-179.

[2] A. Beaudry and A. Pinsonneault, "Understanding User Responses to Information Technology: A Coping Model of User Adaptation," MIS Quarterly, vol. 29, no. 3, 2005, pp. 493-524.

[3] A. Beaudry and A. Pinsonneault, "The Other Side of Acceptance: Studying the Direct and Indirect Effects of Emotions on Information Technology Use," MIS Quarterly, vol. 34, no. 4, 2010, pp. 689-710.

[4] H. Liang, Y. Xue, A. Pinsonneault, and Y. Wu, "What Users Do Besides Problem-Focused Coping When Facing IT Security Threats: An Emotion-Focused Coping Perspective," MIS Quarterly, vol. 43, no. 2, 2019, pp. 373-394.

[5] M.-K. Stein, S. Newell, E. L. Wagner, and R. D. Galliers, "Coping with Information Technology: Mixed Emotions, Vacillation, and Nonconforming Use Patterns," MIS Quarterly, vol. 39, no. 2, 2015, pp. 367-392. 
[6] A. Marakhimov and J. Joo, "Consumer Adaptation and Infusion of Wearable Devices for Healthcare," Computers in Human Behavior, vol. 76, 2017, pp. 135-148.

[7] J. V. Chen, A. Tran, and T. Nguyen, "Understanding the Discontinuance Behavior of Mobile Shoppers as a Consequence of Technostress: An Application of the StressCoping Theory," Computers in Human Behavior, vol. 95, 2019, pp. 83-93.

[8] F. D. Davis, "Perceived Usefulness, Perceived Ease of Use, and User Acceptance of Information Technology," MIS Quarterly, vol. 13, no. 3, 1989, pp. 319-340.

[9] I. Ajzen, "The Theory of Planned Behavior," Organizational Behavior and Human Decision Processes, vol. 50, no. 2, 1991, pp. 179-211.

[10] V. Venkatesh, M. G. Morris, G. B. Davis, and F. D. Davis, "User Acceptance of Information Technology: Toward a Unified View," MIS Quarterly, vol. 27, no. 3, 2003, pp. 425-478.

[11] W. J. Orlikowski and D. C. Gash, "Technological Frames: Making Sense of Information Technology in Organizations," ACM Transactions on Information Systems, vol. 12, no. 2, 1994, pp. 174-207.

[12] E. M. Rogers, Diffusion of Innovations, 4th Edition, Simon and Schuster, 2010.

[13] W. Orlikowski and D. Robey, "Information Technology and the Structuring of Organizations," Information Systems Research, vol. 2, no. 2, 1991, pp. 143-169.

[14] R. S. Lazarus and C. A. Smith, "Knowledge and Appraisal in the Cognition-Emotion Relationship," Cognition \& Emotion, vol. 2, no. 4, 1988, pp. 281-300.

[15] C. A. Smith and L. D. Kirby, "Appraisal as a Pervasive Determinant of Anger," Emotion, vol. 4, no. 2, 2004, pp.

133-138.

[16] R. S. Lazarus and S. Folkman, Stress, Appraisal, and Coping, Springer Publishing Company, 1984.

[17] M. A. Mccoll, H. Lei, and H. Skinner, "Structural Relationships between Social Support and Coping," Social Science \& Medicine, vol. 41, no. 3, 1995, pp. 395-407. [18] S. E. Taylor and A. L. Stanton, "Coping Resources, Coping Processes, and Mental Health," Annual Review of Clinical Psychology, vol. 3, no. 1, 2007, pp. 377-401.

[19] P. A. Thoits, "Stress, Coping, and Social Support Processes: Where Are We? What Next?," Journal of Health and Social Behavior, extra issue, 1995 pp. 53-79.

[20] D. P. Valentiner, C. J. Holahan, and R. H. Moos, "Social Support, Appraisals of Event Controllability, and Coping: An Integrative Model," Journal of Personality and Social Psychology, vol. 66, no. 6, 1994, pp. 1094-1102.

[21] A. DeLongis and T. O'Brien, “An Interpersonal Framework for Stress and Coping: An Application to the Families of Alzheimer's Patients," in Stress and coping in later-life families, Washington, DC, US: Hemisphere Publishing Corp, 1990, pp. 221-239.

[22] G. Caesens and F. Stinglhamber, "The Relationship between Perceived Organizational Support and Work Engagement: The Role of Self-Efficacy and its Outcomes," European Review of Applied Psychology, vol. 64, no. 5, 2014, pp. 259-267.

[23] M. A. Rahim, D. Antonioni, and C. Psenicka, “A Structural Equations Model of Leader Power, Subordinates' Styles of Handling Conflict, and Job Performance,"
International Journal of Conflict Management, vol. 12, no. 3, 2001, pp. 191-211.

[24] S. Folkman and R. S. Lazarus, "Coping as a Mediator of Emotion," Journal of Personality and Social Psychology, vol. 54, no. 3, 1988, pp. 466-475.

[25] N. Gupta and T. A. Beehr, "Job Stress and Employee Behaviors," Organizational Behavior and Human Performance, vol. 23, no. 3, 1979, pp. 373-387. [26] R. D. Iverson, M. Olekalns, and P. J. Erwin, "Affectivity, Organizational Stressors, and Absenteeism: A Causal Model of Burnout and Its Consequences," Journal of Vocational Behavior, vol. 52, no. 1, 1998, pp. 1-23. [27] T. A. Judge, C. J. Thoresen, V. Pucik, and T. M. Welbourne, "Managerial Coping with Organizational Change: A Dispositional Perspective," Journal of Applied Psychology, vol. 84, no. 1, 1999, pp. 107-122.

[28] A. J. Martin, E. S. Jones, and V. J. Callan, "The Role of Psychological Climate in Facilitating Employee Adjustment during Organizational Change," European Journal of Work and Organizational Psychology, vol. 14, no. 3, 2005, pp. 263-289.

[29] P. A. Thoits, "Social Support as Coping Assistance," Journal of Consulting and Clinical Psychology, vol. 54, no. 4, 1986, pp. 416-423.

[30] S. Folkman, R. S. Lazarus, R. J. Gruen, and A. DeLongis, "Appraisal, Coping, Health Status, and Psychological Symptoms," Journal of Personality and Social Psychology, vol. 50, no. 3, 1986, pp. 571-579.

[31] S. Folkman, R. S. Lazarus, C. Dunkel-Schetter, A. DeLongis, and R. J. Gruen, "Dynamics of a Stressful Encounter: Cognitive Appraisal, Coping, and Encounter Outcomes," Journal of Personality and Social Psychology, vol. 50, no. 5, 1986, pp. 992-1003.

[32] L. I. Pearlin and C. Schooler, "The Structure of Coping," Journal of Health and Social Behavior, vol. 19, no. 1, 1978, pp. 2-21.

[33] C. J. Holahan, R. H. Moos, C. K. Holahan, and P. L. Brennan, "Social Context, Coping Strategies, and Depressive Symptoms: An Expanded Model with Cardiac Patients," Journal of Personality and Social Psychology, vol. 72, no. 4, 1997, pp. 918-928.

[34] B. J. Kramer, "Expanding the Conceptualization of Caregiver Coping: The Importance of Relationship-Focused Coping Strategies," Family Relations, vol. 42, no. 4, 1993, pp. 383-391.

[35] J. A. Colquitt, J. A. LePine, R. F. Piccolo, C. P. Zapata, and B. L. Rich, "Explaining the Justice-Performance Relationship: Trust as Exchange Deepener or Trust as Uncertainty Reducer?," Journal of Applied Psychology, vol. 97, no. 1, 2012, pp. 1-15.

[36] A. E. Rafferty and M. A. Griffin, "Perceptions of Organizational Change: A Stress and Coping Perspective," Journal of Applied Psychology, vol. 91, no. 5, 2006, pp. 1154-1162.

[37] S. Folkman and J. T. Moskowitz, "Coping: Pitfalls and Promise," Annual Review of Psychology, vol. 55, no. 1, 2004, pp. 745-774.

[38] T. B. O'Brien, A. DeLongis, G. Pomaki, E. Puterman, and A. Zwicker, "Couples Coping with Stress: The Role of Empathic Responding," European Psychologist, vol. 14, no. 1, 2009, pp. 18-28. 
[39] T. Kurosawa, M. Kato, and T. Kamiya, "RelationshipFocused Coping Patterns of Japanese Child-Rearing Couples," Journal of Relationships Research, vol. 6, 2015, pp. $1-8$.

[40] K. Kayser, M. Sormanti, and E. Strainchamps, "Women Coping with Cancer: The Influence of Relationship Factors on Psychosocial Adjustment," Psychology of Women Quarterly, vol. 23, no. 4, 1999, pp. 725-739.

[41] T. B. O'Brien and A. DeLongis, "The Interactional Context of Problem-, Emotion-, and Relationship-Focused Coping: The Role of the Big Five Personality Factors," Journal of Personality, vol. 64, no. 4, 1996, pp. 775-813. [42] R. D. Iverson, "Employee Acceptance of Organizational Change: The Role of Organizational Commitment," The International Journal of Human Resource Management, vol. 7, no. 1, 1996, pp. 122-149.

[43] P. Neves and A. Caetano, "Social Exchange Processes in Organizational Change: The Roles of Trust and Control," Journal of Change Management, vol. 6, no. 4, 2006, pp. 351364.

[44] M. Vakola and I. Nikolaou, "Attitudes towards Organizational Change: What is the Role of Employees' Stress and Commitment?," Employee Relations, vol. 27, no. 2, 2005, pp. 160-174.

[45] S. Fernandez and H. G. Rainey, "Managing Successful Organizational Change in the Public Sector," Public Administration Review, vol. 66, no. 2, 2006, pp. 168-176. [46] S. W. Floyd and P. J. Lane, "Strategizing throughout the Organization: Managing Role Conflict in Strategic

Renewal," Academy of Management Review, vol. 25, no. 1, 2000, pp. 154-177.

[47] R. Naidoo, "A Communicative-Tension Model of Change-Induced Collective Voluntary Turnover in IT," Journal of Strategic Information Systems, vol. 25, no. 4, 2016, pp. 277-298.

[48] R. Eisenberger, R. Huntington, S. Hutchison, and D. Sowa, "Perceived Organizational Support," Journal of Applied Psychology, vol. 71, no. 3, 1986, pp. 500-507. [49] J. N. Kurtessis, R. Eisenberger, M. T. Ford, L. C. Buffardi, K. A. Stewart, and C. S. Adis, "Perceived Organizational Support: A Meta-Analytic Evaluation of Organizational Support Theory," Journal of Management, vol. 43, no. 6, 2017, pp. 1854-1884.

[50] R. Eisenberger, S. Armeli, B. Rexwinkel, P. D. Lynch, and L. Rhoades, "Reciprocation of Perceived Organizational Support," Journal of Applied Psychology, vol. 86, no. 1, 2001, pp. 42-51.

[51] L. Rhoades and R. Eisenberger, "Perceived Organizational Support: A Review of the Literature," Journal of Applied Psychology, vol. 87, no. 4, 2002, pp. 698-714. [52] C. A. Heaney, J. S. House, B. A. Israel, and R. P. Mero, "The Relationship of Organizational and Social Coping Resources to Employee Coping Behaviour: A Longitudinal Analysis," Work \& Stress, vol. 9, no. 4, 1995, pp. 416-431. [53] S. E. Hobfoll, "Conservation of Resources: A New Attempt at Conceptualizing Stress," American Psychologist, vol. 44, no. 3, 1989, pp. 513-524.

[54] T. A. Revenson and S. J. Lepore, "Coping in Social Context," in Handbook of health psychology, A. Baum, T. A. Revenson, and J. Singer (Eds.), Psychology Press, 2012, pp. 193-217.
[55] H. Barki and J. Hartwick, "Interpersonal Conflict and its Management in Information System Development," MIS Quarterly, vol. 25, no. 2, 2001, pp. 195-228.

[56] L. R. Pondy, "Organizational Conflict: Concepts and Models," Administrative Science Quarterly, vol. 12, no. 2, 1967, pp. 296-320.

[57] K. Ohbuchi and M. Suzuki, "Three Dimensions of Conflict Issues and Their Effects on Resolution Strategies in Organizational Settings," International Journal of Conflict Management, vol. 14, no. 1, 2003, pp. 61-73.

[58] M. A. Rahim, "A Measure of Styles of Handling Interpersonal Conflict," Academy of Management Journal, vol. 26, no. 2, 1983, pp. 368-376.

[59] M. A. Rahim, "Toward a Theory of Managing Organizational Conflict," International Journal of Conflict Management, vol. 13, no. 3, 2002, pp. 206-235.

[60] H. Erkutlu and J. Chafra, "The Mediating Roles of Psychological Safety and Employee Voice on the Relationship between Conflict Management Styles and Organizational Identification," American Journal of Business, vol. 30, no. 1, 2015, pp. 72-91.

[61] N. O. Ndubisi, "Conflict Handling, Trust and Commitment in Outsourcing Relationship: A Chinese and Indian Study," Industrial Marketing Management, vol. 40, no. 1, 2011, pp. 109-117.

[62] M. A. Gross and L. K. Guerrero, "Managing Conflict Appropriately and Effectively: An Application of the Competence Model to Rahim's Organizational Conflict Styles," International Journal of Conflict Management, vol. 11, no. 3, 2000, pp. 200-226.

[63] M. Song, "Conflict Management and Innovation Performance: An Integrated Contingency Perspective," Journal of the Academy of Marketing Science, vol. 34, no. 3, 2006, pp. 341-356.

[64] M. K. Falconier, J. B. Jackson, P. Hilpert, and G. Bodenmann, "Dyadic Coping and Relationship Satisfaction: A Meta-Analysis," Clinical Psychology Review, vol. 42, 2015, pp. 28-46.

[65] D. Weider-Hatfield and J. D. Hatfield, "Relationships Among Conflict Management Styles, Levels of Conflict, and Reactions to Work," The Journal of Social Psychology, vol. 135, no. 6, 1995, pp. 687-698.

[66] T. Coltman, T. M. Devinney, D. F. Midgley, and S. Venaik, "Formative versus Reflective Measurement Models: Two Applications of Formative Measurement," Journal of Business Research, vol. 61, no. 12, 2008, pp. 1250-1262. [67] W. W. Chin and P. R. Newsted, "Structural Equation Modeling Analysis with Small Samples using Partial Least Squares," in Statistical Strategies for Small Sample Research, R. H. Hoyle (Ed), Thousand Oaks, CA: Sage Publications, 1999, pp. 307-341.

[68] E. E. Rigdon, M. Sarstedt, and M. Ringle, "On Comparing Results from CB-SEM and PLS-SEM: Five Perspectives and Five Recommendations," Marketing ZFP, Vol. 39, no. 3, 2017, pp. 4-16.

[69] N. Urbach and F. Ahlemann, "Structural Equation Modeling in Information Systems Research using Partial Least Squares," Journal of Information Technology Theory and Application, vol. 11, no. 2, 2010, pp. 5-40.

[70] C. M. Ringle, S. Wende, and J. M. Becker, "SmartPLS 3.0," Hamburg, Germany, 2014, https://www.smartpls.com 